\title{
Customized Hollow Occular Prosthesis
}

\author{
Sweta Kale Pisulkar ${ }^{1}$, Rohit Mistry², Surekha Godbole ${ }^{3}$, Anjali Borle ${ }^{4}$, Seema Sathe ${ }^{5}$
}

\begin{abstract}
${ }^{1}$ Department of Prosthodontics, Sharad Pawar Dental College and Hospital, Sawangi, Wardha, Maharashtra, India. 2Department of Prosthodontics, Sharad Pawar Dental College and Hospital, Sawangi, Wardha, Maharashtra, India. 3Department of Prosthodontics, Sharad Pawar Dental College and Hospital, Sawangi, Wardha, Maharashtra, India. ${ }^{4}$ Department of Prosthodontics, Sharad Pawar Dental College and Hospital, Sawangi, Wardha, Maharashtra, India. ${ }^{5}$ Department of Ophthalmology, Sharad Pawar Dental College and Hospital, Sawangi, Wardha, Maharashtra, India.
\end{abstract}

\section{INTRODUCTION}

The main objective in restoration of an anophthalmic socket with an ocular prosthesis is to enable the patient to better cope with the difficult process of rehabilitation. ${ }^{1}$ The loss of part of the face effects mainly physical, social, and psychological behaviour of the people affected. ${ }^{2}$ Maxillofacial prosthesis restores and replaces stomatognathic and associated facial structures with artificial substitutes which improves patient's aesthetics, restores and maintains health of the remaining structures, and consequently provides physical and mental well-being. ${ }^{3}$ The loss or absence of an eye which is caused by a congenital defect, irreparable trauma, tumour, a painful blind eye, sympathetic ophthalmia needs evaluation through histologic confirmation of a suspected diagnosis. ${ }^{4}$ Ocular morbidity is a major concern from clinical and socioeconomic perspectives, especially in East Asian countries, in view of its high prevalence and projections for increasing rate and severity of the condition 5 . Ocular prosthesis is a technique sensitive procedure requiring accurate duplication of natural colour, size, contour and ocular orientation which will provide realism and symmetry to the patient. In the current study the reason for blindness was open angle glaucoma. The surgical management of ocular defect includes evisceration, enucleation, or exenteration. Evisceration is a surgical procedure in which the intraocular contents of the globe are removed, leaving the sclera, Tenon's capsule, conjunctiva, extraocular muscles, and optic nerve undisturbed. ${ }^{4}$ Enucleation is the surgical removal of the globe and a portion of the optic nerve from the orbit. ${ }^{4}$ Exenteration is the en-bloc removal of the entire orbit, usually involving partial or total removal of the eyelids, and is performed primarily for eradication of malignant orbital tumors. ${ }^{4}$ There are numerous techniques for processing an ocular prosthesis. ${ }^{6,7,8,9}$ Mathews et al ${ }^{10}$ classified ocular impression and fitting techniques which suggest using an improved technique for custom fabrication of ocular impression tray to obtain a better-fitting custom-made ocular prosthesis. The current article describes rehabilitation of ocular defect of patient who has suffered from trauma and undergone enucleation and describes the various steps involved in fabrication of ocular prosthesis using stock eye. It is characterized according to the contra-lateral eye and gives proper cosmetic results than the stock eye shells. The current case report discusses fabrication of an ocular prosthesis which is custom made and is hollow to reduce weight.
Corresponding Author:

Dr. Sweta Kale Pisulkar,

Associate Professor,

Department of Prosthodontics,

Crown and Bridge,

Sharad Pawar Dental College and Hospital, Sawangi (Meghe), Wardha-442001,

Maharashtra, India.

E-mail:drsweta15@gmail.com

DOI: $10.14260 / j e m d s / 2019 / 788$

Financial or Other Competing Interests: None.

How to Cite This Article:

Pisulkar SK, Mistry R, Godbole S, et al. Customized hollow occular prosthesis- a case report. J. Evolution Med. Dent. Sci. 2019;8(48):3646-3648, $10.14260 /$ jemds $/ 2019 / 788$

Submission 01-10-2019,

Peer Review 12-11-2019,

Acceptance 11-11-2019,

Published 02-12-2019. 


\section{PRESENTATION OF CASE}

For an adult patient with an ocular defect of the left eye. Primary impression was recorded with low-fusing impression compound. Definitive impression was recorded using a customized acrylic tray and polyvinylsiloxane. Final models were obtained, and a wax pattern was fabricated from the model. Iris positioning done using Graph-grid method and the wax trial was done. Processing was done using heat activated acrylic resin to match patients contra-lateral eye shade and aesthetics. The prosthesis was made hollow by lost-salt technique.

\section{Procedure}

1. The patient reported to the department of prosthodontics with an ophthalmic defect, the patient had eye shell in place which was given as a conformer in the socket (Figure 3). The defect was well irrigated and the socket was examined for strictures and inflammation. Frontal Photographs were taken and matching eye shell out of an assorted set was chosen matching with the patient's contra lateral eye.

2. Impression compound Type II (Low fusing DPI Green Stick) was used to record the defect, while in place irreversible hydrocolloid was used to record a moulage of both the eyes. The moulage was poured and a model was obtained on which a wax pattern was made.

3. The wax pattern obtained from the moulage was then used to fabricate a custom tray which will be used for final impression making of the ocular defect. The custom impression tray was provided with relief holes to facilitate retention and release of excess impression material during functional movement of the eye (Figure 1).

4. The custom tray was made with a hollow tube which would facilitate a snugly fit syringe for syringing of light bodied polyvinyl siloxane (Dentsply Reprosil) for definitive impression material. (Figure 1).

5. The eye socket was irrigated with normal saline and lubricated lightly with glycerine. The tray was checked for proper fit and over contouring, light body was syringed into the anopthalmic socket and patient was asked to make movements with the contra-lateral eye which also moved the intrinsic muscles of the defect. (Figure 1).

6. After removal of impression, a two-piece model was made with type IV dental (Kalabhai) stone. A wax pattern was made of the impression obtained and checked in the patient's eye socket (Figure 1).

7. To determine the positioning of the iris in the socket, graphical method was used. Grid lines were drawn on a transparent sheet and facial midline was marked on patients face which corresponded with the midline marked on the graded transparent sheet.

8. Patient was asked to stare at a fixed point in a straight direction, the distance of the pupil of the natural eye was marked on the paper and an arbitrary outline was drawn on the same sheet with an indelible marker. Similar diameter pupil was marked equidistant from the midline marked on the sheet. The sheet was again placed on the patients face and outline was carved on the wax pattern insitu.

9. The eye shell which was selected was then trimmed to fit the wax pattern, the contours were merged and the entire pattern with the eye shell was placed in the socket for trial. (figure 1).

10. Post-trial, a two-piece die was made from the wax pattern which was to be used for final packing. After dewaxing, characterization of the prosthesis was done by adding red veins and intrinsic stains. Packing was done with heat-cure acrylic resin and salt to make it hollow. (figure 2).

11. Final characterization was done with extrinsic stains and the prosthesis was brought to fine polishing. Insertion of the prosthesis was done and patient was given postinsertion instruction. (figure 2).
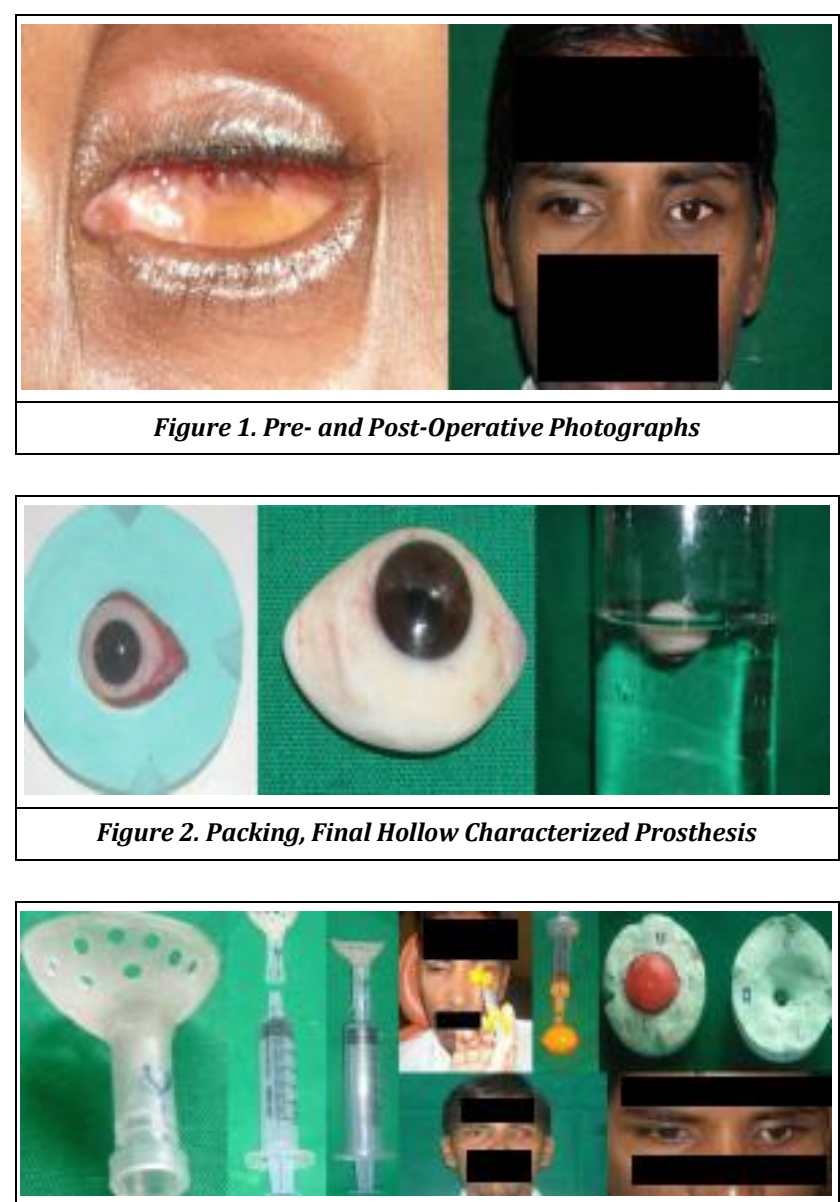

Figure 3. Custom Tray with Snugly Fitted Syringe, Definitive Impression and Stone Model. Wax Pattern Trial with Iris in Place

\section{DISCUSSION}

Open angle glaucoma is second leading cause of blindness in the world, in a rural hospital-based study the incidence of glaucoma was found in $8 \%$ of patients between the age group of 30-35 years of age. ${ }^{11}$ The rehabilitation of patient 34 years old male presented in this report suffered from unilateral glaucoma for which enucleation was done. The rationale for giving this prosthesis in patient is that in such situation is that post-surgical healing is accompanied with shrinkage of socket which causes difficulty in rehabilitation. Also, the custommade ocular prosthesis conforms accurately to the socket as the prosthesis fabrication is based on the existing anatomy of the patient, thus giving benefits of increased adaptation, movement of eye ball, and the exact match of the iris position as that of the adjacent natural eye. ${ }^{12}$ 
The case report involves the use of addition polyvinylsiloxane (Light bodied) for making definitive impression. Sykes in 1996 and Taicher in 1985 advocated the use of addition silicones and techniques for recording impressions, however other materials like ophthalmic alginate, combination of modelling wax and mouth temperature waxes were used, tissue conditioners were also used. 13

Different methods have been suggested to determine the size and position of the iris by visual judgment, using pupillometer, or other callipers. In this case, a transparent graph template was used to accurately locate and position the iris rather than counting on visual assessment alone, which can introduce inter-observer variability because of binocular vision and parallax errors. The method described here is straightforward and can be carried out in any clinical setup. ${ }^{14}$ Acrylic resin is used to fabricate the definitive prosthesis as it is most common material used because of its biocompatibility, esthetic and durability in terms of colour, cost and availability. A custom ocular prosthesis is a good option when reconstruction by plastic surgery or use of osseo-integrated implants is not possible or desired.

\section{CONCLUSIONS}

Ocular defect is not just cause physical deformity but also makes the patient psychologically handicapped. In case of inability to restore such defects with surgery, prosthetic rehabilitation is the best and most sought after option. Custom-made prosthesis allows better aesthetic and functional results to the patient in comparison to stock prosthesis. Follow-up is necessary to check condition and fit of the ocular prosthesis in patients.

\section{REFERENCES}

[1] Ow RK, Amrith S. Ocular prosthetics: use of a tissue conditioner material to modify a stock ocular prosthesis. J Prosthet Dent 1997;78(2):218-22.
[2] Newton JT, Fiske J, Foote 0, et al. Preliminary study of the impact of loss of part of the face and its prosthetic restoration. J Prosthet Dent 1999;82(5):585-90.

[3] Hooper SM, Westcott T, Evans PL, et al. Implantsupported facial prosthesis provided by a maxillofacial unit in a U.K. regional hospital: longevity and patient opinions. J Prosthodont 2005;14(1):32-8.

[4] Perman KI, Baylis HI. Evisceration, enucleation and exenteration. Otolaryngol Clin North Am 1988;21(1):17182.

[5] Tidake P, Madan P. Peripheral retinal findings in high myopia in a tertiary hospital. JDMIMSU 2016;11(4).

[6] Sykes LM, Essop ARM, Veres EM. Use of custom-made conformers in the treatment of ocular defects. J Prosthet Dent 1999;82(3):362-5.

[7] Bartlett SO, Moore DJ. Ocular prosthesis: a physiologic system. J Prosthet Dent 1973;29(4):450-9.

[8] Kale E, Mese A, Izgi AD. A technique for fabrication of an interim ocular prosthesis. J Prosthodont 2008;17(8):65461.

[9] Brown KE. Fabrication of an ocular prosthesis. J Prosthet Dent 1970;24(2):225-35.

[10] Mathews MF, Smith RM, Sutton AJ, et al. The ocular impression: a review of the literature and presentation of an alternate technique. J Prosthodont 2000;9(4):210-6.

[11] Tidake P, Sharma S. Clinical profile and management of primary open-angle glaucoma patients above 40 years: a rural hospital-based study. J Datta Meghe Inst Med Sci Univ 2017;12(1):1-6.

[12] Gunaseelaraj R, Karthikeyan S, Kumar MN, et al. Custommade ocular prosthesis. J Pharm Bioallied Sci 2012;4(Suppl 2):S177-9.

[13] Shenoy KK, Nag PVR. Ocular impressions: an overview. 2007;7(1):5-7.

[14] John AV, Anilkumar S, Rajesh C, et al. A novel technique of custom ocular prosthesis fabrication. J Oral Res Rev 2016;8(2):82-5. 